\title{
A IMPORTÂNCIA DE INSERIR NO CURRÍCULO DAS ESCOLAS DE SALVADOR O CONTEÚDO DIVERSIDADE CULTURAL
}

\author{
Tatiane Araujo Santana ${ }^{1}$ \\ Telma Regina dos Reis de Assis ${ }^{2}$ \\ Zoraide Silva dos Santos ${ }^{3}$
}

\begin{abstract}
RESUMO
O objetivo desta pesquisa é reconhecer a importância de inserir no currículo das escolas de Salvador o conteúdo diversidade cultural da referida cidade através de reflexões sobre a sua relevância nos aspectos sociais, educacionais e científicos. A cultura é uma característica do ser humano e da comunidade a que pertence. Logo, é impossível concebê-la, desatrelando-a deste, assim, como se torna difícil a definição do homem sem a sua origem enraizada em uma determinada cultura. Para a concepção desta pesquisa foi utilizada o metodologia da pesquisa bibliográfica em livros, jornais e revistas. Conclui-se que é importante inserir no currículo das escolas de Salvador o conteúdo diversidade cultural, pois não se pode conceber, uma educação sem cultura, nem uma cultura sem a educação, pois, ambas se completam, nas funções de instruir e constituir o indivíduo, neste caso, inserção do conteúdo diversidade cultural no currículo das escolas da cidade de Salvador faz-se necessário para que seja valorizada a cultura, latente da região.
\end{abstract}

Palavras Chave: Currículo. Diversidade Cultural. Educação.

\begin{abstract}
The objective of this research is to recognize the importance of inserting in the curriculum of schools in Salvador the cultural diversity content of that city through reflections on its relevance in social, educational and scientific aspects. Culture is a characteristic of the human being and the community to which he belongs. Therefore, it is impossible to conceive it, unraveling it from it, thus, how difficult it is to define man without his origin rooted in a certain culture. For the design of this research, the methodology of bibliographic research in books, newspapers and magazines was used. We conclude that it is important to include in the curriculum of schools in Salvador the content of cultural diversity, as it is impossible to conceive, an education without culture, nor a culture without education, since both are complementary, in the functions of instructing and constituting the individual, in this case, insertion of the cultural diversity content in the curriculum of schools in the city of Salvador is necessary for the culture, latent in the region, to be valued.
\end{abstract}

Keywords: Curriculum. Cultural diversity. Education.

\section{Introdução}

\footnotetext{
${ }^{1}$ Mestra em Ciências da Educação pela Faculdade Interamericana de Ciências Sociais - FICS. Tecnologia em Radiologia pela UNIRB. Docente pela UNIME/ UNIDAS EFIB. E-mail tatiane.conta123@gmail.com

2 Doutoranda em Ciências da Educação pela Faculdade Interamericana de Ciências Sociales (FICS). Mestre em Ciências da Educação pela Faculdade Interamericana de Ciências Sociales (FICS). Especialista em Metodologia e Didática do Ensino Superior pela Faculdade Católica de Ciências Econômicas da Bahia (FACCEBA). Licenciada em Pedagogia Plena pela Faculdade Regional de Filosofia, Ciências e Letras de Candeias (FAC). Licenciada em Matemática pela Universidade Salvador (UNIFACS). Docente pela Secretaria Estadual de Educação de Salvador Ba..Email:telmaassis@rocketmail.com

${ }_{3}$ Mestra em Ciências da Educação pela Faculdade Interamericana de Ciências Sociais - FICS. Especialista em Metodologia do Ensino Superior - UNITER. Especialista em Imaginologia com ênfase em Tomografia Computadorizada e Ressonância Magnética - FAVENI. Tecnóloga em Radiologia UNIRB. Técnica em Radiologia e Diagnóstico por Imagem-INSSJT. Email: zoraidessantos@hotmail.com
} 
Não se pode definir Salvador como uma cidade que vive das glórias do passado, mas que nesta procura define as metas para outro amanhã. A diversidade cultural do povo baiano está diretamente ligada à dança, a música, a arte, à fé, ao sagrado, etc. E a presença dessas diversas manifestações culturais pode ser vista como referência na construção da cultura de um povo, pois:

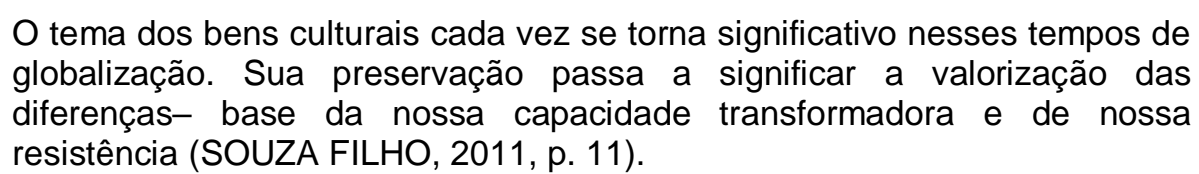

A sociedade atual percebe a importância de respeitar o patrimônio cultural. Muitas vezes, a nostalgia de um passado majestoso impede o desenvolvimento do município, barrando o crescimento do mesmo e a possibilidade de uma melhor qualidade de vida para as novas gerações. As manifestações culturais existentes, e até as ainda preservadas da mácula humana, expressam todo esse universo de sentimento, de identidade, de ideologia que constrói o homem e as sociedades. Em sua pluralidade, produz a beleza do diverso no uno, do coletivo no indivíduo. É, sem dúvidas, uma riqueza que merece ser preservada, valorizada e, constantemente, resinificada, pois:

Cultura é uma expressão da construção humana. A cultura é construída
através do diálogo entre as pessoas no dia a dia. Nessa interação social é
construído gradativamente símbolos e significados que tem sentido a essas
pessoas, e são compartilhados entre elas. A construção de uma cultura está
repleta de elementos e significados que vão identificar esse povo como
pertencente a uma determinada comunidade ou região, diferenciando-os de
outras comunidades, surge assim, a identidade cultural (ARIAS, 2002, p.
103).

Sendo a cultura uma característica do ser humano e da comunidade a que pertence onde torna-se difícil a definição do homem sem a sua origem enraizada em uma determinada cultura, surge à necessidade da realização de uma pesquisa e/ou estudo voltado para a importância das manifestações culturais do vigente na cidade de Salvador onde a adoção da consciência da interação com a cultura, em sua diversidade, estabelece parcerias para a melhoria da educação e a formação de cidadãos conscientes, comprometidos, com uma identidade sólida e consistente.

\section{A Cultura no Processo de Aprendizagem}

Educação e Cultura duas instâncias fundamentais da constituição do ser humano, sua relação, sem sombra de dúvidas é fundamental, pois uma educação que não se fundamenta na cultura, na realidade de vida de seus educandos, não 
alcança seus objetivos, pois trabalha pautada em conteúdos, em referências paralelas àquilo que seus educandos vivem. Uma cultura que não educa, subtrai, destrói; quando não se moderniza, não se ressignifica ${ }^{4}$, ela estagna o homem, pois deixa-o preso em tradições, na maioria das vezes, esquecidas em um passado, em um mundo que ele não viveu, foi apenas inserido, sem nem mesmo poder ou ter a oportunidade de entender aquilo que está participando.

Ambas têm seu papel na formação do ser humano, uma (a cultura) o acompanha, o conceitua; a outra (a educação), o aperfeiçoa, educa seus instintos. Nisto, nota-se a importância de uma eventual relação da cultura com a educação, uma relação sadia, de respeito e, principalmente de parceria.

Sem sombra de dúvidas é uma questão que não pode ser omitida dentro dos currículos, haja vista que o próprio Estatuto da Criança e do Adolescente (ECA) aponta o respeito à cultura como uma das metas primordiais, onde a educação está inclusa, seja em qual instância for da sociedade no momento em que diz que:

É dever da família, da comunidade, da sociedade em geral e do Poder Público assegurar, com absoluta prioridade, a efetivação dos direitos referentes à vida, à saúde, à alimentação, à educação, ao esporte, à profissionalização, à cultura, à dignidade ao respeito, à liberdade e à convivência familiar e comunitária (BRASIL, 2006, p. 53)

Um povo sem cultura, não é um povo: é um aglomerado de pessoas sem história, sem conduta, sem algo que possa caracterizá-los como gente, constituintes de uma sociedade organizada. Ora, é lógico que cada sociedade tem a sua forma de existir, mas para que esta seja formada, inicialmente, o homem tem de ser educado (MÜLLER, 2003).

Não há povo sem cultura, não há homem sem cultura e sem povo. Uma identidade tem de estar implícita dentro de cada ser humano e a educação, via natural de construção do seu pensamento crítico-reflexivo, que, por sua vez, aponta caminhos para este, mostrando-lhe a melhor forma de ser cidadão, é a via de regra para que o homem, neste caso, o educando, se torne 'gente ${ }^{5}$ '.

Porém, para que o homem seja efetivamente consolidado e conscientizado de sua condição de ser social, o processo educacional, tão natural em sua vida, tem de existir pautado em uma base sólida: a sua cultura. Uma cultura que nada mais é do

\footnotetext{
${ }^{4}$ Dar um sentido diferente a alguma coisa.

${ }^{5}$ Número indeterminado de pessoas.
} 
que a sua realidade de vida, os seus costumes, a sua forma de falar, andar, comer, pensar, dançar etc.

Neste princípio, fica difícil se pensar numa educação que diz fazer o seu papel, que é educar, sem considerar o meio que o educando está inserido e aquilo que ele celebra em seu dia-a-dia, pois:

Não podemos esquecer que a questão da identidade cultural, de que fazem parte a dimensão individual e a de classes dos educandos cujo respeito é absolutamente fundamental na prática educativa progressiva, é problema que não pode ser desprezado (FREIRE, 1996, p. 19).

Infelizmente, a utopia educacional existente nas maiorias das cidades tidas como históricas do Brasil, prevê a implantação de novos modos de educar, na valorização de culturas e linguagens importadas, pois considera-se a vivência dos educandos, no que tange a sua cultura, no seu cotidiano, suficiente para que o mesmo entenda o processo social ao qual está inserido, podendo valorizá-lo e preservá-lo.

Daí vê-se a necessidade do conhecimento de coisas novas e do eventual esquecimento daquilo que é denominado o cotidiano dos alunos. Um erro, pois é impossível a concepção de um processo educacional paralelo à bagagem que os alunos trazem. Se não há o uso, a celebração, não há atrativos, pois o educando não se identifica com aquilo que está aprendendo. Resultado: não há educação, não se efetiva o real aprendizado e as bases são construídos numa estrutura frágil.

Outro fator importante neste sentido é o abandono das raízes culturais dos educandos e, posteriormente, a imposição de práticas pedagógicas voltadas para essa importação, no intento de mostrar que a realidade de vida dos educandos não condiz com o perfil atual das grandes potências, do mundo moderno, tendências atuais, avanços necessários que não podem se relacionar com comportamentos antigos, antiquados, fora de moda. Nesta concepção, nota-se que "o discurso dominante, em resumo, deprecia a pedagogia enquanto forma de produção cultural, assim como menospreza a cultura popular" (GIROUX, SIMON, 1999, p. 126). A partir destas ideologias apresenta-se a proposta que diz:

Está na hora de começar a pensar a educação para além da metáfora organizacional da escola, tal como a concebe a maior parte da população. De formular e pôr em prática um sistema educativo cuja função seja oferecer um ambiente de aprendizagem rico e socialmente integrado, em que todos os indivíduos encontrem um lugar para aprender (SANCHO, 2002, p. 52). 
A relação educação e cultura é viável e, acima de tudo, necessária. Porém, deve-se estabelecer a concepção primordial da educação como agente transformador e conscientizador, promotor da valorização e preservação do patrimônio de uma determinada sociedade. Ações podem e devem ser executadas, visando, principalmente, a celebração das diversas manifestações culturais que povoam o espírito humano, caracterizando-o, manifestações que definem a ele e a comunidade em que está inserido, no cotidiano da sala de aula.

A construção de um currículo flexível, onde a promoção do bem-estar comum e a inserção, não do que o educando quer, por conveniência, aprender, mas, daquilo que ele vive. Sem sombra de dúvidas haverá aí muitos resultados. Uma educação que reconheça a cultura, em sua pluralidade, em sua diversidade, em sua multiculturalidade, fazendo dela um instrumento do aprendizado, gera a satisfação, e todos serão favorecidos o educando e a sociedade, porque:

\begin{abstract}
Para os alunos, o tema Pluralidade Cultural oferece oportunidades de conhecimentos de suas origens como brasileiro e como participante de grupos culturais específicos. Ao valorizar as diversas culturas que estão presentes no Brasil, propicia ao aluno a compreensão de seu próprio valor, promovendo sua autoestima como ser humano pleno de dignidade, cooperando na formação de autodefesas a expectativas indevidas que lhe poderiam ser prejudicadas. Por meio do convívio escolar possibilita conhecimentos e vivências que cooperam para que se apure sua percepção de injustiças e manifestações de preconceito e discriminação que recaiam sobre si mesmo, ou que venha a testemunhar - e para que desenvolva atitudes de repúdio a essas práticas (BRASIL, 2000, p. 51).
\end{abstract}

O interessante, também, a ser mencionado, é a questão da diversidade cultural. Muitos professores não têm a competência, ou dizem não saber trabalhar uma diversidade tão grande em uma sala de aula, também, formada por uma diversidade de tantas ideias. Porém, o que se pode observar é que o mais importante não é a competência, mas o chamado 'jogo de cintura' .

Ora, que há um grandioso universo cultural, isto é inquestionável, todavia o trabalho em sala de aula deve se pautar na valorização desta diversidade; a celebração de culturas e manifestações específicas deve ser realizada a partir do regionalismo, da realidade que os alunos vivem. Este é o ponto chave da inserção da cultura no processo educacional, a identificação e, eventual, conscientização, do todo e a localização dos alunos no específico, singular através de:

Práticas educacionais, destrezas e valores que, de uma maneira explícita ou oculta, são estimulados, as crianças vão se sentido membros de uma

\footnotetext{
${ }^{6}$ Flexibilidade para encarar alguma coisa, sair de dificuldades, e é uma expressão coloquial
} 
comunidade. Pouco a pouco, tornam-se conscientes, de uma série de peculiaridades que as identificam e dos laços que as unem como grupo de iguais. Por contraposição, descobrem que algumas das características físicas, idiomas, costumes, modos de pensar das quais eles comungam, são diferentes das de outras pessoas e grupos humanos. Todos os seres humanos, no momento em que se encontram diante de outras pessoas com características físicas muito diferentes ou com outro idioma materno, ou com costumes diferentes, adquirem algum grau de consciência de sua existência como grupo diferenciado; compreendem que compartilham uma certa visão do mundo com seu grupo de iguais e, ao mesmo tempo, que existem outras maneiras de pensar e de ser (SANTOMÉ, 2003, p. 168)

Em se tratando das culturas esquecidas nos currículos escolares, não se pode deixar de fazer uma referência à situação dos afrodescendentes e de sua riquíssima cultura, nem tanto esquecida, mas, na maioria das vezes negadas.

Sem sombra de dúvidas não há como medir a força desta rica tradição cultural, muitas vezes, estereotipada e rotulada por práticas que nada têm a ver com as raízes negras, uma religiosidade, difundida, simplesmente, pela força dos ritmos e pelo poder das práticas, na maioria delas caracterizadas pela magia e 'macumba'.

Porém, o esquecimento gerou, por longos anos, a desvalorização desta riqueza e o eventual esquecimento das manifestações que, na maioria das vezes, estão enraizadas na vida dos educandos, pois tudo o que ele respira e vive.

\section{Educação e Identidade Cultural}

Educação em si, traz consigo a importância em trazer para o mundo pessoas pensantes, questionadoras, que busquem incessantemente compreender o mundo que as cercam, a sociedade em que vivem e principalmente que se identifiquem com sua cultura e povo.

Assim, falando especificamente em educação e a relacionando a cultura, podemos citar a Lei de Diretrizes e Bases da Educação Nacional (LDBEN) 9394/1996 em seu Art. 10: "A educação abrange a todos os processos formativos que se desenvolvem na vida familiar, no trabalho, nas instituições de ensino e pesquisa, nos movimentos sociais e organizações da sociedade civil e nas manifestações culturais".

Desta forma, é possível compreender melhor o que vem a ser educação e tudo aquilo que possa estar ligada a esta para venha acontecer de forma consistente, significativa e construtiva para o desenvolvimento pleno do educando. Entrelaçando educação com identidade cultural, faz-se necessário compreender a relevância em que todo o educador busque meios que possam levar seus alunos e 
entender de onde surgiu a história do seu povo, as suas tradições e que possam perceber todo esse conjunto em herança da sua cidade, estado.

Não se pode culpar a educação por este processo de negação, pois a história nacional é uma prova desse processo, mas ela muito contribuiu para esta realidade, por exemplo, utilizando livros didáticos que desenhavam a história do continente africano, simplesmente, relatando a escravidão, ou a primitividade de tribos negras, pouco civilizadas. Além de outros conteúdos que pouco demonstraram a riqueza, da diversidade e da sabedoria deste povo; além da desvalorização da identidade cultural de seus alunos, como visto anteriormente, já que as raízes foram esquecidas, raízes profundas, legadas do continente africano, pois:

O pouco caso com a cultura africana se reflete na sala de aula. O segundo
maior continente do planeta aparece em livros didáticos somente quando o
tema é escravidão, deixando capenga a noção de diversidade de nosso
povo e minimizando a importância dos afrodescendentes. Por isso em 2003 ,
entrou em vigor a Lei oㅡ 10.639 , que tenta corrigir essa dívida, incluindo o
ensino de história e cultura africanas e afro-brasileiras nas escolas
(GENTILE, 2005, p. 42).

Sobre esta questão da regulamentação da obrigatoriedade da temática 'História e Cultura Afro-brasileira', "a lei prevê que os conteúdos referentes à história e cultura afro-brasileira serão ministrados no âmbito de todo o currículo escolar, em especial nas áreas Educação Artística e de Literatura e História Brasileiras" (ALMEIDA, 2005, p. 12). A inclusão desta temática é necessária e representa, acima de tudo, uma reparação a erros que foram cometidos no passado.

A relação educação e cultura e, mais, a influência da segunda sobre a primeira é um ponto interessante a ser considerado. Há, por mais discreto que seja uma influência da cultura em relação à educação. O que ocorre é o fechamento das escolas a esta realidade. Ora, se os estudantes, partícipes de certas culturas estão inseridos no contexto escolar, automaticamente, a cultura está ali presente.

Porém, mesmo diante desta presença, que pode ser passiva, não há o reconhecimento nem a valorização desta, aí sim, existe a tentativa da desconstrução dos conceitos enraizados, adquiridos no decorrer do cotidiano de cada aluno 'bagagem de vida7' -, com a valorização de conhecimentos que nada têm a ver com esta herança e que, muitas vezes, vêm a tentar descaracterizá-la. O pior disso tudo, é que em certos casos o objetivo é alcançado e:

\footnotetext{
${ }^{7}$ Experiência pessoal, conhecimento adquirido com o tempo; experiência de vida.
} 
Portanto, repito, do que se tem medo? De sermos identificados como a parte 'menor' da oposição binária. Muitos mestiços se fazem passar por brancos; muitos intermediários e proletários valorizam os atributos e produtos burgueses; muitos cristãos omitem-se; muitos/ as homossexuais disfarçam-se; muitas mulheres reproduzem lógicas masculinas de existência. É perturbador perceber o quanto um sujeito ou grupo cultural se submete para forjar-se normal (PEREIRA, 2003, p. 22).

Em todo o intento quanto aos processos, anteriormente referidos, existe um agente diferencial, que pode reverter toda essa situação de opressão e imposição. 0 educador, ator direto do processo educacional, tem nas mãos as possibilidades de reverter todo esse quadro.

Mesmo diante de algumas impossibilidades, como, por exemplo, a insensibilidade dos currículos e de alguns gestores, o trabalho em sala de aula, onde há efetivamente a construção do saber, na relação professor-aluno, pode ser flexibilizado atendendo a algumas necessidades específicas. Nestas entram a cultura de vida dos educandos, pois:

$\mathrm{Na}$ escola, o professor é envolvido não só por essa cultura geral sendo também exposto ao que podemos chamar de cultura escolar. De fato, a escola cria ou produz, ela própria, um saber específico, considerando, de um lado, a confrontação entre os conhecimentos sistematizados disponíveis na cultura geral e de outro, aqueles menos elaborados, provenientes tanto da 'lógica' institucional quanto das características da profissão como ainda da vida cotidiana escolar (PENIN, 1994, p. 35).

O professor, dentro do processo cultural, é, sem sombra de dúvidas, quem faz o diferencial. Ele não é o detentor do poder, porém ele pode utilizar de sua autonomia dentro de sua classe para verter o aprendizado às áreas mais necessitadas do conhecimento, integrando e trabalhando as 'bagagens de vida' de seus alunos, proporcionando, finalmente, a construção de um espaço de saber, através de um caminho de liberdade. Para isso depende um fator imprescindível como o respeito e a tolerância e:

Quero aqui trazer as ideias de tolerância muito mais como movimento de guerra, como movimento de esforço e não de conformismo. Como estratégia de liberdade que supõe aceitação da diferença, a vivência da reciprocidade e a ruptura da dominação da homogeneidade. É preciso entender que homogeneidade é conflito e que a vivência com o conflito é danosa (MARTINELLI et.al., 2001, p. 70).

É este o conflito que o professor, na maioria das vezes, passa em sala de aula. As perguntas quanto ao atendimento à diversidade de pensamentos, de saberes, de interesses e, principalmente, de culturas, são constantes. Mas, as respostas são encontradas no dia-a-dia do trabalho pedagógico. 
Esta é uma temática interessante e nenhuma regra de didática jamais poderá definir a função do professor neste processo de reconstrução das culturas dentro de sala de aula, haja vista que as realidades variam e, a partir delas, o trabalho pode ser delimitado.

É interessante insistir na ideia da ressignificação da cultura no processo educacional, mais ainda, no reconhecimento da influência desta em todas as áreas deste processo (avaliação, disciplina, rendimento escolar, evasão etc.). Faz-se interessante ainda, nesta celebração do particular, a exposição da situação de cada indivíduo no geral, no global, mostrando o valor de sua célula (gema), como constituinte de algo maior, que o define como povo, como sociedade, discutindo sobre a sua identidade cultural.

O professor traz para a sala de aula a sua cultura, a sua forma específica de ensinar, no entanto, nele deve estar embutido o sentimento do respeito e porque não dizer do aprendizado das diversas formas que seus alunos têm de ver o mundo, sua cultura e opinião.

Se o princípio básico da valorização das identidades culturais em sala de aula está no reconhecimento, o professor, mesmo que não comungue daquela realidade, por opção ou por falta de oportunidade, deve trabalhar com seus alunos a tão necessária conscientização.

Conscientização que gera o respeito ao diferente, ao outro, seja para com o próprio professor seja para com o colega, ao que ele vive e celebra, mesmo que vá de encontro às suas ideologias, a preservação daquilo que o define como 'gente'. Essa situação pode ser ilustrada através da uma proposta interessante, explicando que:

Existe um lugar sagrado, onde aprendiz e mestre se encontram. É neste espaço encantado, quase mágico que o que antes era mistério passa a ser revelado de maneira surpreendente. Às vezes foram precisos minutos de dedicação, horas de concentração, dias de frustração, anos de construção e quem sabe até mesmo algumas vidas de elaboração para a preparação do conteúdo a ser revelado. Os personagens podem ser variados, os temas diversos, os cenários podem várias do Oriente ao Ocidente. O que permanece perene, inabalável ao longo dos séculos é o processo do encontro de aprendizagem. Encontro que consegue inundar a alma do aprendiz de um misto de coragem e curiosidade ao mesmo tempo que enleva o conteúdo como se este fosse uma encarnação do mundo de ideias. O desafio do mestre é desenvolver nas mãos a habilidade de um parturiente capaz de valorizar e acreditar na possibilidade de acessar com suas mãos o conhecimento, traduzindo assim, nas leis do corpo, aquilo que somente pode ser inscrito pela alma, a sabedoria. Portanto, por meio deste encontro, o mestre pode dar vida a algo que respira eternamente no espírito (QUIRINO, 2004, p. 41). 
Pensar na cultura no processo de aprendizagem, torna-se necessário refletir a respeito da escola e suas possibilidades, da escola e seus entraves e principalmente da escola e as características dos seus educandos, na perspectiva de analisar minuciosamente qual o tipo de trabalho poderá ser realizado na instituição de ensino para que a cultura venha ser de grande relevância no aprendizado de todos.

Desta forma, todos os envolvidos necessitam compreender o verdadeiro significado de cultura, sendo uma tarefa que requer muita força, disposição e constante análise de tudo a sua volta. Portanto, a cultura não pode ser compreendida como um conjunto de conhecimentos e valores estáticos que precisam ser transmitidos a outrem ou às gerações futuras, mas como uma produção ativa, a qual é sucinta uma relação entre o binômio produção e contestação das identidades e dos grupos sociais (MOREIRA, 2001).

Assim, as escolas precisam refletir acerca de como está sendo feito a inserção da cultura para o aprendizado dos seus educandos e não podem mais silenciar tudo aquilo que aparenta ser diferente dos discursos culturais predominantes tendo uma pluralidade evidente do mundo com uma necessidade clara e direta com outras formas de produção cultural. Portanto, os conteúdos elencados na estrutura das diferentes disciplinas precisam compreender a gritante realidade em discutir cultura com seus alunos e professores e consequentemente dar conta de uma relação histórica e socialmente que poderá ou não ocorrer.

Enfim discutir em sala a cultura de sua região com parte integrante do seu ser, do seu viver e que cada um poderá contribuir para a sua conservação afetiva histórica, como também leva à todos muito conhecimento, aprendizado e que poderá contribuir de forma direta para a sua formação quanto cidadão, consciente da sua existência no mundo e com sabedoria suficiente para compreender o que espera e quer para o seu futuro.

\section{Os Parâmetros Curriculares Nacionais, Pluralidade Cultural e Educação Multicultural, Frente as Suas Contradições}

Os Parâmetros Curriculares Nacionais (PCN) na versão preliminar distribuída para apreciação pela comunidade acadêmica consistem em uma série de 
prescrições curriculares para o ensino fundamental II, dando continuidade à primeira parte do documento relativo aos $1^{\circ 0}$ e $2^{\circ}$ ciclos, voltado às séries iniciais.

Dotada de estrutura semelhante (documento introdutório, introdução aos temas transversais e documentos referidos a cada área curricular), a proposta em pauta sofre algumas das mesmas limitações curriculares apontadas por autores tanto no que diz respeito à reduzida consulta prévia à comunidade acadêmica para sua elaboração inicial, quanto ao excesso de prescrições em seu bojo e ao viés psicológico em sua abordagem (MOREIRA, 2001).

Questionamentos em relação à viabilidade de se tratar a pluralidade cultural como tema transversal sofreram também, avançados que manifestam receio de que a "impregnação" de tal proposta no trabalho, nas diferentes áreas, possa ser tão tênue a ponto de se tornar invisível.

A relevância em se promover a conscientização acerca da educação multicultural como necessária à promoção de cidadãos críticos e participativos, em sociedade cada vez mais multiculturais, deveria, dessa forma, ser enfatizada no interior de todas as áreas, bem como no trabalho relativo às representações sociais de docentes sob pena de reduzir-se a um "imperativo moral" consensualmente aceito no currículo formal, não efetivamente implementado nas práticas curriculares vivenciadas.

O documento em questão é dividido em duas partes: na primeira, apresentam-se a justificativa, o estado atual dos trabalhos com a temática, as contribuições trazidas pelos conhecimentos em áreas diversas (são citados fundamentos éticos, jurídicos, históricos, geográficos, sociológicos, antropológicos, de linguagens, representações populacionais, psicológicos e pedagógicos) e os objetivos gerais do ensino fundamental.

$\mathrm{Na}$ segunda parte, trata-se das implicações das posturas discutidas em termos de conteúdos e seus critérios de seleção. Aponta-se que os conteúdos receberam o tratamento por blocos, nos quais são propostos núcleos temáticos, que incorporam "avanços do conhecimento, reivindicações antigas de movimentos sociais e divulgação de direitos civis, sociais e culturais estabelecidos na Constituição Federal" (BRASIL, 1997, p.23).

Tais temas são elencados sob os seguintes títulos: Pluralidade Cultural e a Vida dos Adolescentes no Brasil, Pluralidade Cultural na Formação do Brasil e Direitos Humanos, Direitos de Cidadania e Pluralidade. 
Os assuntos são, por sua vez, subdivididos em categorias, tais como: a organização familiar como instituição em transformação no mundo contemporâneo, a vida comunitária como referência afetiva, forma de organização e base de relações econômicas em diferentes regiões, as relações com o tempo e com o espaço por seres humanos de diferentes origens culturais, a educação em diferentes grupos humanos, a atitude de voltar a atenção para o ponto de vistas dos grupos sociais, 0 ser humano como agente social e produtor de cultura, as muitas linguagens como fator de identidade de grupos, e assim por diante.

Uma primeira aproximação dos temas e subtemas elencados permite uma visualização inicial de contradições discursivas no que se refere à educação multicultural e aos construtos de identidade nacional e de pluralidade de identidade culturais discutidos no texto (VEIGA-NETO, 1996).

Por exemplo, ao citar Pluralidade Cultural e a Vida dos Adolescentes no Brasil, uma ruptura parece ocorrer entre a primeira e a segunda parte do tema: adolescentes aparecem como categoria identitária ${ }^{8}$ "mestra", abstrata, homogênea, e a impressão que se tem é que pluralidade cultural irá ser estudante em relação a seu impacto sobre essa identidade - a de ser adolescente. Contradizendo autores tais como Grant (1997), Hall (1997), Mclaren (1997) e Fatherstone (1997), a identidade "adolescente" não é vista em termos de sua articulação aos outros marcadores identitários singulares de gênero, classe social, raça, padrões socioculturais, inserção, histórica etc.

Ainda, a partir dos temas e subtemas elencados para o trabalho com a pluralidade cultural, pode-se observar que tentativas de reconhecimento da pluralidade identitária de grupos socioculturais e a busca de superação da homogeneização cultural não parecem incluir docentes e discentes na problemática apontada. Trata-se, ao contrário, de falar da pluralidade cultural em termos que a afastam, nas dimensões temporais e espaciais, da realidade concreta do cotidiano escolar.

A diversidade cultural é tratada em um tom narrativo que a limita a fatos históricos ou a ritos e costumes referentes àqueles grupos destacados. Enfatiza-se o "outro", sem que se promova a conscientização da pluralidade cultural e dos estereótipos a ela relacionados, dentro do próprio espaço escolar e das práticas sociais mais amplas, em uma perspectiva intercultural crítica (CANEN, 1997).

\footnotetext{
${ }^{8}$ Relacionado com o conjunto de características que define e caracteriza algo ou alguém.
} 
Este fato bastante evidente, por exemplo, na parte em que se refere à descrição dos blocos de conteúdos, como seleção que "visa à oferta, para a criança, de vivências e informações, que propiciem a percepção de uma situação social e cultural mais ampla e complexa do seu mundo imediato" (BRASIL, 1997, p.22).

Ainda que o parágrafo prossiga especificando a relevância de se levarem em conta as características culturais locais, a ênfase na necessidade de compreensão da complexidade do país reduz a pluralidade cultural a uma perspectiva macro, em detrimento de sua articulação com os universos culturais dos alunos que chegam às escolas.

Nesse tipo de enfoque presente no documento analisado, em que a pluralidade cultural é vista como "estando lá, mas não aqui", predomina a perspectiva de educação multicultural que privilegia a abordagem de "feira de culturas", de conhecimento de padrões culturais plurais para aceitação interpessoal, de acordo com uma visão fenomenológica (CANEN, 1997).

Enfatiza-se o conhecimento das formas com que diferentes grupos tratam da relação tempo-espaço, da organização familiar, dos ritos, da vida comunitária, das múltiplas linguagens empregadas, das expressões artísticas etc. Essa apresentação leva à ideias de grupos culturais puros, locais, acabando por reforçar uma homogeneidade cultural (desta vez, no âmbito dos grupos culturais específicos) que deveria, no que diz respeito a intenções, ser combatida. Desconhecem-se, pois, a dinamicidade, os choques, os conflitos e as transformações pelos quais grupos culturais constroem identidades híbridas ${ }^{9}$, terceiras culturas (GRANT, 1997).

A perspectiva de uma educação multicultural para o conhecimento de práticas culturais diversificadas e para a promoção da aceitação cultural, em uma linha fenomenológica é percebida no decorrer de vários trechos contidos no documento em análise (CANEN, 1997). Fala-se, por exemplo, que se deve "aprender a posicionar-se de forma a compreender a relatividade de opiniões, preferências, gostos, escolhas, e aprender a respeitas o outro" (BRASIL, 1997, p. 17).

Da mesma forma, aponta-se que compreender que diferentes etnias desenvolvem diversas formas de organização de destas e celebrações permita a aproximação que o adolescente pode fazer de sua própria vivência. Também, afirma-se que se deve "oferecer ao aluno, e construir junto com ele, um ambiente de respeito, pela aceitação; de interesse, pelo apoio à sua expressão" (lbid, p. 18).

\footnotetext{
${ }^{9}$ Que provém de espécies diferentes.
} 
Esse tom que reduz o tratamento da diversidade cultural a uma perspectiva da aceitação interpessoal está presente, também, em diferentes partes do discurso referente à língua como fator de identidade para grupos étnicos.

No sentido de desfio de preconceitos associados a dialetos e sotaques, são, no entanto, tratadas em diversas passagens do texto na qualidade de conhecimento acerca dos processos de aquisição de uma segunda língua e o significado dessa aquisição do ponto de vista social, cultural e econômico bem como acerca de "regionalismos e expressões utilizadas por grupos étnicos em seu cotidiano" (Ibidem., p.35).

\section{Lei 10.639/03 e o Ensino da História e Cultura Afro-Brasileira e Africana}

No Brasil, prevaleceram, durante séculos, formas violentas de exploração da mão de obra, graças à permanência da escravidão. Para sobreviver, era preciso reagir a essas violências e encontrar alternativas ainda que não fosse possível conquistar a liberdade. Um país formado por uma sociedade multicultural, constituída em quase sua totalidade por descendentes de africanos, mostrou-se indiferente aos danos políticos, sociais, morais, psicológicos e educacionais consequência do longo período de escravidão que houve no Brasil, pois:

Após a abolição da escravatura isso ainda se perpetuou, mesmo que sendo
de forma camuflada, ato de manipulação sempre presente nas mãos dos
governantes e de uma política desigual, discriminatória, fruto de um extenso
branqueamento da sociedade (PINTO, 1993, p. 73).

Buscando minimizar tanto tempo de sofrimento e bloqueio de direitos entre os povos, querendo indiretamente reparar, tentar reconhecer e valorizar a história, cultura e identidade do povo africano e seus descendentes, foi implantada a lei 10.639 no ano de 2003, nas Diretrizes Curriculares nacionais para a Educação das Relações Étnico-Raciais e para o Ensino de História e Cultura Afro Brasileira e Africana.

A Educação das Relações Étnico-Raciais visa principalmente educar e levar para as estudantes informações a respeito do seu vínculo étnico-racial, buscado garantir respeito e seguridade aos seus direitos, na valorização da sua identidade, dando possibilidades para a consolidação e consistência da democracia brasileira cada vez mais justa e digna para todo, pois: 
O Ensino de História e Cultura Afro Brasileira e Africana objetiva a garantia dos direitos dos cidadãos afro-brasileiros, em consequência 0 reconhecimento quanto a identidade, história e cultura. Ressaltando a grande importância da cultura africana, como as demais que já conhecemos para formação do povo brasileiro (GOMES, 2001, p. 59).

Assim, as diretrizes já citadas, tentam corrigir os inúmeros sofrimentos causados pelo regime escravista e por uma política excludente e principalmente preconceituosa, que infelizmente mesmo com os grandes avanços que ocorreram e continuam acontecendo, ainda assim perduram até os nossos dias atuais.

A demanda por reparações a que o Estado e a sociedade tomem medidas para ressarcir os descendentes de africanos negros, dos danos psicológicos, materiais, sociais, políticos e educacionais sofridos pelo regime escravista, bem como em virtude das políticas explicitas ou tácitas de branqueamento da população, de manutenção de privilégios exclusivos para grupos com poder de governar e de influir na formulação de políticas no pós-abolição. Visa também que tais medidas se concretizem em iniciativas de combate ao racismo e toda sorte de discriminação (BRASIL, 2004).

Assim com essa lei, o Estado através da educação visa garantir: a igualdade de direitos para o pleno desenvolvimento das pessoas, enquanto cidadãos e também profissionais, aquisição de competências e de conhecimentos consideráveis essenciais para a continuidade e consequente sucesso na educação escolar. Mesmo tendo total conhecimento que o racismo, as desigualdades e a discriminação ocorrem tanto dentro como fora das escolas, pois:

Torna-se necessário enfatizar o principal papel das instituições de ensino que vem a ser o incessante combate a estas e demais atitudes que levem a fata de respeito, desvalorização e discriminação do negro inserido em uma sociedade, a qual todos possuem direitos e deveres, que devem ser devidamente cumpridos (PAULA e COSTA, 2007, p. 19).

Ao não reconhecer o outro, o diferente ignora-se as relações de poder, a hierarquização da sociedade que garante privilégios a uns em detrimento de outros, miserabilidade e sujeição de outros. Justamente no contexto escolar de relações entre alunos, professores e demais funcionários que as diferenças deverem ser evidenciadas e valorizadas.

Desta forma, através da Lei 10639, busca-se refletir a respeito da palavra reconhecer e valorizar, tendo consciência dos seus reais significados e importância principalmente no contexto educacional, pondo em prática de maneira clara, objetiva, consistente e que leve para todos outros sentidos como: igualdade e 
respeito, aonde todos os educadores precisam ser mediadores na desconstrução do mito da democracia racial em busca da superação da desigualdade étnico-racial, na valorização a cultura e identidade africana, criando possibilidades e condições para que todo estudante negro seja tratado com dignidade e respeito.

\section{A Importância de Inserir no Currículo das Escolas de Salvador o Conteúdo Diversidade Cultural}

Ao abordar sobre diversidade cultural, refere-se a uma grande, interessante e curiosa mistura de crenças, tradições e demais aspectos que fazem do Brasil, do estado Bahia e especificamente na cidade de Salvador, um conjunto que traz ao passar das gerações heranças indissociáveis, ricas e que mostra todos os dias 0 retrato de um país resultante de uma grande miscigenação.

Assim, torna-se necessário, principalmente na capital baiana, inserir no seu currículo uma constante abordagem em relação a diversidade cultural, quanto ao seu significado, importância e sua presença no cotidiano de todos e, deste modo levar para todos os educandos conhecimentos e informações indispensáveis para a vivencia em sociedade. Desta forma será ofertada:

\footnotetext{
A possibilidade de abrir espaço para uma discussão construtiva, trocando experiências, elevando conhecimentos e valorizando todo um povo, despertando um olhar reflexivo no que tange ao procurar conhecer suas origens, memorias proporcionando cada vez mais um aprendizado sadio, instrutivo e concreto (MOURA, 1998, p. 108).
}

Sendo assim é proporcionada a possibilidade de eliminar preconceitos ainda presentes e que foram arraigados durante toda a história do Brasil e que com a cidade de Salvador não vem a ser tão diferente.

Para todo o educador, vem a ser de extrema importância dominar de forma clara e objetiva qualquer conteúdo que o mesmo venha a transmitir para os seus educandos, para que estes compreendam e assimilem tudo o que for falado e relatado, dando assim sentido e significado ao mesmo, buscando sempre relacionar cada assunto ao cotidiano do aluno e sem deixar de considerar seus conhecimentos prévios para que aconteça um aprendizado prazeroso, enriquecedor e significativo para todos.

Ao tempo em que o educador busca levar para o âmbito escolar questões relevantes para todos, que geralmente falam de igualdade, diversidade, discriminação, questão racial e aspectos da cultura afro-brasileira, é imprescindível 
inserir no currículo das escolas de Salvador enfoques sobre a diversidade cultural que seja algo trabalhado com clareza e relevância.

Abordagens trazendo discussões benéficas para todos e que perpassam toda uma história de um povo que de forma direta contribuiu para todo o conjunto que resultou em tudo o que temos hoje, e que por muito tempo foi menosprezado, mesmo o Brasil, sendo um país constituído em quase sua totalidade por descendentes africanos (MATOS, 2007).

Trabalhar no currículo das escolas de Salvador abordagens sobre a diversidade cultural, exige não só falar quem foram os africanos e outros aspectos, mas mergulhar juntamente com os educandos na sua cultura para que cada um se veja, construa a sua própria identidade, se aceitem e compreendam cada vez mais a formação do povo brasileiro como também toda uma miscigenação, que resultou em uma grande diversidade cultural com pessoas com características físicas tão diferentes umas das outras, mas pertencentes a um mesmo conjunto de povos.

Igualmente, dentro de todo esse contexto torna-se essencial debater um tema que se encontra constantemente presente na vida de todos e onde muitos passaram ou ainda passam por isso que vem a ser o racismo e consequentemente 0 preconceito e a discriminação. De acordo com tudo o que se observa nas discussões anteriores desta pesquisa torna-se importante destacar a diversidade de culturas e povos em espaços diversos possibilitando uma reflexão mais crítica e consistente em relação ao destaque que é dado para uma parcela da sociedade na produção histórica, enquanto uma outra parcela fica esquecida no que diz respeito a evolução da política e economia do nosso país, mostrando desta forma também as desigualdades sociais.

O docente precisa favorecer aos seus discentes novas vivencias e descobertas que possibilitem aos mesmos confrontar, trocar, negar, reafirmar, sentir, olhar e discutir as singularidades, diferenças, línguas, tradições, expressões, jeito de ser e crer. E desta forma favorecer para a construção de uma sociedade mais humana, justa e democrática. $O$ docente precisa favorecer para um espaço onde os educandos possam se expressar, se descobrir e analisar a sociedade na qual se encontra inserido.

Ao falar da inserção da disciplina de história com conteúdo e/ou currículo com abordagens sobre a diversidade cultural nas escolas de Salvador pode-se relacionar no atual contexto em que se está relatando o ensino de história e cultura afro- 
brasileira. E dentro desta proposta é possível apontar a Lei 10.639/2003, nas Diretrizes Curriculares Nacionais, que foi elaborada com a finalidade de promover políticas favoráveis à reparação, reconhecimento e valorização da história, identidade e cultura dos africanos e seus afrodescendentes.

Pode-se compreender que o maior objetivo vem a ser a desconstrução do mito da democracia racial no brasil, e exaltar a valorização da diversidade como base para a superação da desigualdade étnico-racial ainda presentes em muitas instituições escolares baianas uma vez que:

A Educação das Relações Étnico-Raciais visa educar e informar os estudantes com relação ao seu pertencimento étnico-racial, garantindo respeito aos seus direitos, valorizando sua identidade e possibilitando assim a consolidação da democracia brasileira (LIMA, 2012, [s/p]).

O Ensino de História e Cultura Afro-Brasileira e Africana tem por finalidade garantir os direitos dos cidadãos afro-brasileiros, assim como, o reconhecimento e a valorização da sua identidade, cultura e história, ressaltando a importância da cultura não somente africana, como também a indígena destacando e a diversidade cultural na formação da sociedade baiana. Portanto, através da Lei 10.639/2003, o Estado:

Visa garantir através da educação a igualdade de direitos para o total
desenvolvimento de todos os indivíduos, enquanto cidadãos e profissionais,
a valorização do patrimônio histórico-cultural afro-brasileiro, e também a
aquisição das competências e os reconhecimentos considerados
indispensáveis para a permanência e êxito na educação escolar (SOUZA,
$2004,[\mathrm{~s} / \mathrm{p}]$ ).

Posteriormente, a Lei $11.645 / 2008$, reforça a mesma lógica da lei 10.639/2003, todavia ressaltando a orientação quanto à temática indígena também, essas leis não são apenas instrumentos de orientação para o combate à discriminação, mas também são leis afirmativas, no sentido de que reconhecem a escola como lugar da formação de cidadãos e afirmam com maior veemência a grande importância da escola em promover a necessária valorização das diferenças, a partir da compreensão do direito a ter direito.

Mesmo com lei educacional que busca valorizar a história do povo africano e seus descendentes, valorizando a cultura de um todo compreendem que o racismo mesmo no mundo que se vive atualmente com tantas transformações e avanços tecnológicos, ainda perdura e encontra-se presente tanto dentro do âmbito escolar, com fora dele em diversos meios sociais. 
Apesar disso não é possível deixar de ressaltar o papel que as instituições de ensino e seu corpo docente e discente possuem na discussão sobre a diversidade cultural, combate a tanta discriminação e falta de respeito. Uma vez que as mesmas sendo reconhecidas como espaço democrático de produção e disseminação de conhecimentos e responsável em oferecer educação para todos, independente da cultura, raça ou religião, as escolas precisam se comprometer cada vez mais a buscar eliminar a discriminação e o preconceito, buscando promover a superação do sentimento de inferioridade socioeconômica tão presentes e relacionada a cor, raça, etc. Mesmo com tudo isso ainda:

Existem escolas que não buscam trabalhar todo esse contexto de forma efetiva, podemos encontrar professores que mesmo cientes do seu papel perante os seus educandos possuem preconceitos com os mesmos e ainda sim ignoram a lei 10.639/2003 e o que diz seus princípios (MUNANGA, 2011, p. 46)

Essas escolas fazem do ambiente educacional algo onde muitos alunos não sentem abraçados e sendo tratados de forma igualitária perante os demais colegas. Mediante a tudo o que está sendo exposto no momento, analisando e discutindo, pode-se perceber que perante o século $X X I$, onde as pessoas se encontram cercadas de tantas evoluções, transformações e avanços tecnológicos que fascinam crianças e jovens, a escola continua com o constante desafio em despertar nos discentes o encanto pelos estudos, em querer conhecer, aprender e compreender, enfim pela descoberta.

Isso pode ser entendido por muitas instituições de ensino, ainda continuarem com o seu currículo ainda muito tradicionalista, devido a julgar questões consideradas importantes e que em muitas situações não vem a ser compatível com desejo, necessidade e principalmente fora da realidade dos seus educandos. Desta forma, o currículo remete a todo educador uma constante reflexão a respeito de tudo aquilo que possa fazer da sala de aula um ambiente agradável, atrativo e rico em informação e conhecimento, pois:

Torna-se imprescindível que o educador reflita sobre o seu cotidiano e medidas necessárias para aproximar seus educandos cada vez mais de uma realidade de grandes diferenças culturais que não se encontra distante das instituições de ensino (FREITAS, 2012, p. 43).

O currículo para a educação de todos e em destaque para o ensino de história e cultura afro-brasileira e africana valorizando a diversidade cultural, 
necessita estar ligado diretamente as situações ratificadas acima e vivenciadas por muitos educandos.

Sejam elas dentro e/ou fora da escola, que mostre e leve a todos a significativas reflexões que precisam ser apresentadas para a construção de uma nova sociedade munida de pessoas conscientes dos seus direitos e deveres, e que lutem para que prevaleça a dignidade, o respeito e a incessante luta contra 0 racismo e os diversos tipos de preconceitos existentes em nosso país e no mundo (LOPES, 2006).

Portanto não somente em cultura afro, mas em outras disciplinas também, o currículo precisa deixar de seu algo fragmentado aonde a escola insiste em preocupar-se apenas em explorar os saberes, horários, reservando um determinado tempo para cada disciplina, mas necessitando ser algo dinâmico, mostrando desafios que devem ser solucionados com a cooperação de todos, ou seja, vivenciado por inteiro, de forma indivisível, podendo ter diversas escolhas e criando muitas estratégias.

Dentro de toda essa questão envolvendo conceitos, polêmicas e realidade, percebe-se o currículo com um documento de identidade, constituído de significados que apresentam a escola, aquele povo que refletem a sociedade e suas relações com o mundo, e é urgente que:

O ensino de História e Cultura Afro-Brasileira fazendo referências a diversidade cultural, seja realizado nas instituições de ensino conforme a realidade de cada uma, seja de forma multidisciplinar seguindo determinados critérios e se for interdisciplinar da mesma forma (LOPES, 2006, p. 35).

Faz-se necessário analisar, buscar modificar e mostrar caminhos para uma sociedade mais justa e com cidadãos pensantes, questionadores e com bagagem suficiente para compreender tantas desigualdades com ocorreram e ainda ocorrem no país principalmente com as classes mais desfavorecidos.

Aqui no contexto em destaque refere-se à diversidade cultural, os negros e seus entraves que desde muito tempo busca a liberdade, a igualdade e também valorização e respeito. Almeja-se uma agregação de valores, conhecimentos, aprendizado, troca de experiências para se tornar um trabalho enriquecedor, significativo para todos e que leve para um importante e grande conhecimento e aprendizado que sempre são necessários. Porque os desafios estão aí para serem 
enfrentados e superados por uma sociedade ainda preconceituosa e só através da educação tudo isso poderá ter um desfecho diferente.

\section{Considerações Finais}

Após esta pesquisa pode-se afirmar que existe uma relação entre educação e cultura no contexto educacional, com grandes possibilidades em desenvolver esta aliança de forma clara, objetiva, consistente e inovadora destacando a importância da valorização da identidade cultura e os parâmetros curriculares nacionais ressaltando a pluralidade cultural e educação multicultural, frente as suas contradições.

Cultura é reflexo e modelo à muitas culturas, à muitas cidades que tentam resgatar sua tradição popular. A cultura baiana é espelho e produtora de cultura e personalidades. Diante disto, uma medida emergencial de flexibilização na inserção do conteúdo diversidade cultural da educação faz-se necessária, uma vez que a valorização e a atenção dada a esta herança por instâncias de fora, supera as ações e intenções das instituições baianas.

Através destas abordagens apresenta-se a relevância de inserir no currículo das escolas de Salvador abordagens sobre a diversidade cultural trazendo reflexões fundamentais para a realização e êxito deste, já que as escolas perante tantos avanços e reformulações na educação ainda persistam em manter uma pratica pedagógica, tradicional, arcaica e que de forma direta não contribui em muita coisa para o crescimento e desenvolvimento dos seus educandos. Faz- se necessário reconhecer que a cultura se modifica de acordo a uma trajetória que envolve toda a essência sentimental, perpassando as barreiras do sacro e do profano, do erudito e do popular, tendo em cada ser humano uma parcela definitiva de sua constituição. Como se na coletividade existisse as particularidades de pensamentos, expressos em manifestações que visam unir este em um único proceder: humanizar.

Com visto, todo este processo só é possível a partir do entendimento do conceito de cultura e suas diversas possibilidades, também, de um estudo aprofundado da relação educação e cultura, pois o entendimento da realidade regional e específica da influência da diversidade cultural na educação de Salvador, foi é entendida a partir de uma pesquisa aprofundada, sucedida, de um trabalho de campo junto aos atores envolvidos, tanto no âmbito cultural com no educacional.

A inserção da diversidade cultural na matriz curricular das escolas de Salvador pode contribuir para conscientização da importância da cultura na 
formação da identidade de um povo percebendo a importância do resgate dos valores humanos como alternativa viável para a efetivação do integral crescimento intelecto-social do cidadão. Em se tratando da educação, por mais que ela negue a influência da diversidade Cultural no seu cotidiano, desde que haja a presença de um educando, sempre haverá cultura nas escolas da cidade de Salvador-Ba.

\section{Referências:}

ALMEIDA, C. A. L. A obrigatoriedade da temática "História e Cultura Afro-brasileira". In.: Revista Linha Direta: Educação por escrito. Seção Intratexto. São Paulo: Rona Editora, 2005.

ARIAS, P. G. La cultura. Estrategias Conceptuales para comprender a identidad, la diversidad, la alteridad y la diferencia. Escuela de Antropologia Aplicada. São Paulo: UPS-Quito. Ediciones Abya-yala.2002.

BRASIL. Ministério da Educação e do Desporto. Conselho Nacional de Educação. Câmara da Educação Básica. Exposição de motivos ao encaminhamento das diretrizes e bases da educação nacional. Brasília, DF: CNE, 1997.

BRASIL, Parâmetros Curriculares Nacionais: Pluralidade Cultural e Orientação Sexual. Secretaria de Educação Fundamental. 2. ed. Rio de Janeiro: DP\&A, 2000.

BRASIL. Diretrizes Curriculares Nacionais para a Educação das Relações Étnico-Raciais e para o Ensino de História e Cultura Afro-Brasileira. Brasília: Secretaria de Políticas de Promoção da Igualdade Racial, 2004.

BRASIL. Presidência da República. Secretaria Especial dos Direitos Humanos. Conselho Nacional dos Direitos da Criança e do Adolescente. Plano Nacional de Promoção, Proteção e Defesa do Direito de Crianças e Adolescentes à Convivência Familiar e Comunitária. Brasília, DF: CONANDA, 2006.

CANEN, A. Formação de professores: diálogo das diferenças. Ensaio: avaliação e políticas públicas em educação. Rio de Janeiro: Revista da Fundação Cesgranrio, 1997

FREIRE, P. Pedagogia da Autonomia: saberes necessários à prática educativa. São Paulo: Paz e Terra, 1996.

FREITAS, F. A diversidade cultural como prática na educação. Curitiba: Inter Saberes, 2012.

GENTILE, P. África de todos nós. In: Nova Escola: a revista do professor. Ano XX - № 187. São Paulo: Editora Abril, 2005.

GOMES, N. L. Educação cidadã, etnia e raça: o trato pedagógico da diversidade. In: CAVALLEIRO, Eliane. Racismo e anti-racismo na educação: repensando nossa escola. São Paulo: Selo Negro, 2001. 
GRANT, N. D.C. Alguns problemas de identidade e educação: um exame comparativo da educação multicultural. Rio de Janeiro: Educação Comparada. 1997.

LIMA, M. N. M. Escola Plural: a diversidade está na sala: Formação de professores/as em história e cultura afro-brasileira e africana. 3. ed. São Paulo: Cortez; Brasília: UNICEF, 2012.

LOPES, A. L. Currículo, escola e relações ético-raciais. In: Educação africanidades Brasil. Brasília: MEC - SECAD - UnB - CEAD - Faculdade de Educação 2006.

MARTINELLI, M. L.; RODRIGUES ON, M. L.; MUCHAIL, S. T. (Org.). O uno e o múltiplo nas relações entre as áreas do saber. 3. ed. São Paulo: Cortez, 2001.

MATTOS, R. A. História e cultura afro-brasileira. Contexto: São Paulo, 2007.

MOREIRA, A F. A recente produção científica sobre currículo e multiculturalismo no Brasil (1995-2000): avanços, desafios e tensões. São Paulo: Revista Brasileira de Educação, 2001.

MOURA, C. História do negro brasileiro. 5 ed. São Paulo: Ática, 1998

MUNANGA, K. Superando o racismo na escola. Brasília: Ministério da Educação, 2011.

PENIN, S. T. de Souza. A aula: espaço de conhecimento, lugar de cultura. 5. Ed. Campinas, SP: Papirus, 1994.

PEREIRA, M. R. A Boina Alienígena. Sujeito, Identidade e Diversidade Cultural. In.: Revista Presença Pedagógica. São Paulo: Editora Dimensão, Maio/ Junho 2003.

PAULA, A. R. COSTA, C. M. A hora e a vez da família em uma sociedade inclusiva. Brasília: Ministério da Educação, Secretaria de Educação Especial, 2007.

PINTO, R. P O Movimento negro em São Paulo: Luta e identidade. Tese de Doutorado, São Paulo: FFLCH/USP, 1993.

SANCHO, J. M. A Diversidade da escola ou a diversidade da educação. In.: Pátio: Revista Pedagógica. Porto Alegre - RS: Editora Artmed, 2002.

SANTOMÉ, J. T. As culturas Negadas e Silenciadas no Currículo. In.: Silva, Tomaz Tadeu (Org.). Alienígenas na Sala de Aula: uma introdução aos estudos culturais em educação. 5. ed. - Petrópolis, RJ: Vozes, 2003.

SOUZA, J. Políticas da identidade afro-brasileira em Curitiba: festa e rito. Curitiba: Departamento de Antropologia, UFPR, 2004.

SOUZA FILHO, R. Gestão Pública e Democracia: A Burocracia em Questão. Rio de Janeiro: Lumen Juris, 2011. 
VEIGA-NETO, A. A ordem das disciplinas. Tese de doutorado no Programa de Pós-Graduação em Educação da UFRGS. Porto Alegre: UFRGS, 1996. 